Cuadernos de Historia Contemporánea

ISSN: 0214-400X

http://dx.doi.org/10.5209/CHCO.54306

\title{
Estados Unidos y la preparación de la Transición en España
}

José Antonio Montero Jiménez ${ }^{1}$

Rodríguez Jiménez, Francisco Javier, Delgado Gómez-Escalonilla, Lorenzo y Cull, Nicholas J. (eds.): U.S. Public Diplomacy and Democratization in Spain. Selling Democracy?, New York, Palgrave MacMillan, 2015.

Rosendorf, Neal M.: Franco Sells Spain to America. Hollywood, Tourism and Public Relations as Postwar Spanish Soft Power, New York, Palgrave MacMillan, 2014.

Las percepciones sobre la política exterior de los Estados Unidos están rodeadas de mitos y estereotipos. En mayo de 2003, todavía bajo la impresión de los atentados contra las Torres Gemelas, Tony Judt deploraba el éxito de que disfrutaba en Francia un libro del periodista Thierry Meyssan, en que cuestionaba la veracidad del ataque contra el Pentágono el 11 de septiembre de 2001: "En Francia -escribía- existe una audiencia para las teorías más paranoicas sobre Estados Unidos"². España no se queda a la zaga, como pone de manifiesto el hecho de que en 2009, el periodista y escritor Javier Cercas daba por descontada, en su Anatomía de un instante, la aquiescencia, si no la implicación, de Estados Unidos ante el golpe de Estado del 23-F: "nadie dejó de entender lo único que podía entenderse: que Estados Unidos aprobaba el golpe y que, si éste acababa triunfando, el gobierno norteamericano sería el primero en celebrarlo"3. La difusión de ambas obras pone de manifiesto la necesidad de actualizar los estudios históricos en torno a la actuación internacional de Norteamérica, de manera que se ciñan a las evidencias documentales disponibles, y huyan de las típicas aproximaciones dicotómicas.

Durante décadas, los estudios sobre las relaciones hispano-estadounidenses en el franquismo pudieron dividirse en acríticos, hipercríticos o llevados por preocupaciones exclusivamente nacionales. Del lado norteamericano, los primeros análisis de los pactos de 1953 tenían un sentido eminentemente práctico, buscando la manera de paliar los efectos derivados de la asociación con una dictadura como la franquista, sin cuestionar en el fondo la legitimidad de ese vínculo. Del lado español, y sobre todo entre los opositores al franquismo, cundía la tendencia contraria. Influidos por el paradigma del "imperialismo cultural", escritores como Manuel Vázquez Montalbán o los periodistas Eduardo Chamorro e Ignacio Fontes, arremetían contra Estados Unidos por utilizar la bandera de la democracia como un banderín de enganche, bajo el que se escondía el interés por expandir el modelo capitalista

\footnotetext{
Universidad Complutense de Madrid (España)

E-mail: josemont@ghis.ucm.es

2 Recogido en JUDT, Tony: Cuando los hecho cambian. Artículos, 1995-2010, Madrid, Taurus, 2015, p. 232.

3 CERCAS, Javier: Anatomía de un instante, Barcelona, Mondadori, 2009, p. 76.
} 
de sabor americano. En último término, los trabajos pioneros de la historiografía española, aunque meritorios, estaban motivados por una agenda puramente nacional, y se incluían dentro de las corrientes renovadoras de la historiografía volcadas en la desmitificación de la dictadura. Así lo declaraba Ángel Viñas en 1981, cuando buscaba sustituir "las visiones embellecedoras de los nostálgicos por la contrastación de la realidad en el ejercicio del Poder"4. Tampoco en estos casos el nexo entre Washington y Madrid establecido a mediados de 1950 parecía dejar en muy buen lugar a los estadounidenses ${ }^{5}$.

El fin de la Guerra Fría propició una renovación, a nivel internacional, de los estudios sobre la proyección exterior de Estados Unidos, que diluyó la rigidez de los marcos interpretativos preexistentes. La presencia internacional de "lo norteamericano" dejó de asociarse de forma exclusiva con los objetivos estratégicos de su gobierno, o con el papel de éste como agente de los grandes intereses económicos. La americanización comenzó a verse como un fenómeno multiforme impulsado por una larga lista de agentes -gobiernos, empresas, fundaciones, escritores, actores, deportistas, etc.- que no sólo podían tener intereses contrapuestos, sino que en muchas ocasiones ejercían su papel de transmisores culturales de forma inconsciente e involuntaria. Asimismo, se trataba de un proceso biunívoco, en el que los receptores de la influencia estadounidense ejercían un papel que iba más allá de la resistencia a determinadas formas de aculturación: mientras el mundo se americanizaba, los Estados Unidos, a su vez, se mundializaban como resultado de su creciente interacción con las partes más remotas del planeta. Tales alteraciones en el enfoque de los trabajos sobre historia internacional de Estados Unidos se debieron fundamentalmente a dos factores: la disponibilidad de un volumen creciente de documentación primaria, tanto norteamericana como extranjera; y la realización de estudios que abandonaban las perspectivas amplias, para centrarse en la influencia americana sobre áreas geográficas concretas. Sólo así pudo percibirse no sólo que el propio gobierno estadounidense actuó en más de una ocasión de forma errática, a consecuencia de la cantidad de instancias oficiales que, con objetivos a veces difícilmente reconciliables, participaban en el proceso de toma de decisiones; sino también que, como recuerda Jessica Gienow-Hecht, a la hora de hablar de americanización resulta muy difícil la generalización, pues "cada nación europea se enfrentó de manera peculiar al desafío de la Guerra Fría y al influjo de la cultura americana después de la II Guerra Mundial"6.

4 VIÑAS, Ángel: Los pactos secretos de Franco con los Estados Unidos. Bases, ayuda económica, recortes de soberanía, Madrid, Grijalbo, 1981, p. 13.

5 Dos buenos repasos en torno a la evolución de los estudios sobre relaciones España-Estados Unidos en la segunda mitad del siglo XX son: DELGADO, Lorenzo y LEÓN AGUINAGA, Pablo: "De la primacía estratégica a la difusión del modelo americano: Estados Unidos y la España del franquismo", en BARRIO, Á., HOYOS, Jorge de, y SAAVEDRA, R. (eds.): Nuevos horizontes del pasado. Culturas, políticas, identidades y formas de representación, Santander, Publican, 2011, pp. 171-185. Y LEÓN AGUINAGA, Pablo: "Ecos lejanos. La historiografía sobre ‘Estados Unidos y el Mundo’ durante la Guerra Fría”, en DELGADO, L., MARTÍN DE LA GUARDIA, R., y PARDO, R. (eds.): La apertura internacional de España. Entre el franquismo y la democracia (1953-1986), Madrid, Sílex, 2016, pp. 87-125.

6 GIENOW-HECHT, Jessica C.E.: “'¡No, no somos así!’ El despliegue de la cultura americana durante la Guerra Fría”, en NIÑO, A. y MONTERO, J.A. (eds.): Guerra Fría y propaganda. Estados Unidos y su cruzada cultural en España y América Latina, Madrid, Biblioteca Nueva, 2012, pp. 49-84; cita en la p. 59. La misma autora ha realizado un modélico estado de la cuestión sobre la evolución de la historiografía de la americanización en "Shame on US? Academics, Cultural Transfer, and the Cold War, Diplomatic History, vol. 24, no 3 (2000), pp. 465-494. 
Desde finales de los años noventa, estas nuevas orientaciones han influido de manera limitada, pero significativa, en el estudio de las relaciones hispanoestadounidenses. Un grupo de historiadores económicos, encabezados por Nuria Puig y Adoración Álvaro Moya, han rastreado los nexos entre la inversión norteamericana en la Península Ibérica y la modernización de las empresas en España, independientemente de si esos lazos se forjaron con ayuda o al margen de las autoridades americanas. De calado han sido también los resultados de los distintos proyectos de investigación dirigidos por Lorenzo Delgado y Antonio Niño, centrados en las transferencias culturales trasatlánticas, y más concretamente en los agentes de americanización actuantes en territorio español durante el pasado siglo. La mayoría de los trabajos publicados en los últimos diez años se han centrado, no obstante, en los esfuerzos dirigidos o coordinados por el gobierno norteamericano a través de sus organismos de propaganda y relaciones culturales -lo que se conoce como diplomacia pública-, bien durante las dos guerras mundiales, bien durante el período 1945-1960. Gracias a ellos se han comenzado a conocer tanto la implantación institucional del aparato propagandístico, como sus medios -uso de publicaciones, prensa, revistas, radio, centros culturales-, sus mensajes, y algunos de sus programas específicos -becas Fulbright, Foreign Leader Program, etc. Asimismo, se han establecido colaboraciones fructíferas, en forma de publicaciones conjuntas, con expertos europeos y estadounidenses en estas materias, como Nicholas Cull o Giles Scott-Smith. Más allá de ceñirse al ángulo oficial de la americanización, estos trabajos se veían afectados por dos limitaciones: apenas habían superado el marco cronológico de los años cincuenta, ni analizado el impacto real de la diplomacia pública estadounidense en la sociedad española. Se trataba de un problema metodológico, condicionado por las fuentes de información disponibles: la documentación americana daba pistas, sobre todo, del entramado burocrático, y su localización era peculiarmente complicada para el período posterior a $1955^{7}$. Los dos trabajos aquí reseñados -U.S. Public Diplomacy and Democratización in Spain y Franco Sells Spain to America- suponen un paso adelante en la superación de algunos de estos condicionantes.

El volumen colectivo editado por Francisco Javier Rodríguez, Lorenzo Delgado y Nicholas Cull persigue un objetivo a la vez ambicioso y polémico: replantear el papel ejercido por Estados Unidos en la Transición española de la dictadura a la democracia, combinando la variable político-estratégica -imperante hasta el momento-con la propagandística y la cultural. La pregunta de partida sería: “¿Hasta qué punto contribuyeron las campañas estadounidenses de diplomacia pública desplegadas en España al proceso de democratización?" (p. 6). A la hora de responder, los autores se proponen superar la barrera cronológica de los años cincuenta, considerando el franquismo en su totalidad, e incluso adentrándose en los primeros años del período democrático. Para ello aprovechan la labor de acopio documental realizada por varios de los contribuyentes al libro en los últimos años, mediante la visita a distintas bibliotecas presidenciales y la consulta de fondos secundarios de los Archivos Nacionales estadounidenses. Los editores pretenden también probar las posibilidades de "internacionalización" del caso español, matizando el axioma de la

Véase CORRALES MORALES, David: “La americanización a debate. Una visión crítica sobre su desarrollo y repercusión en el mundo académico a través de la diplomacia pública”. Trabajo inédito de Fin de Licenciatura, Departamento de Historia Contemporánea, Universidad Complutense de Madrid, 2013, pp. 115-119. 
"excepcionalidad" de los vínculos entre España y Estados Unidos, respecto de los que tenían otros países europeos. Algo que puede hacerse, como Jessica GienowHecht, negando la existencia de un patrón europeo, o bien encontrando puntos de conexión entre España y otras naciones del entorno. En último término, para medir la influencia de cualquier factor en la democratización de España es necesario tener en cuenta el papel de sus ciudadanos, y por tanto prestar atención a uno de los componentes esenciales de la diplomacia pública, según la definición de Nicholas Cull: la "escucha"; "He ahí el Santo Grial de los ejecutores de la diplomacia pública: estar, siguiendo las conocidas palabras de Edward R. Murrow, director de la United States Information Agency, 'listo en el despegue' dela política, y no limitarse a 'los aterrizajes de emergencia"" 8 .

El británico Giles Scott-Smith considera en su capítulo el papel que la promoción de la democracia ha ocupado como objetivo en la política exterior estadounidense. Históricamente, que los Estados Unidos hayan cultivado una imagen de sí mismos como adalides de uno de los modelos democráticos más acabados no significa que su acción internacional tuviera que basarse, siguiera oficialmente, en un proselitismo democrático activo. Hasta entrado en siglo XX, la expansión de la democracia, salvo en las áreas geográficas circundantes, se entendía como una especie de elemento de soft power, destinado meramente a despertar la envidia o los deseos de imitación de otros países. Fue el wilsonismo el que, durante la I Guerra Mundial, concibió por primera vez la política exterior como una cruzada para lograr "un mundo seguro para la democracia", y desde entonces hasta hoy no han dejado de percibirse las consecuencias de este cambio, materializadas en, al menos, tres tipos de contradicciones. Como apunta el propio Scott-Smith, "puede implicar elementos de coacción" (p. 30) que acaban siendo contraproducentes, como se puso de manifiesto ya en época de Wilson en relación con la Revolución Mexicana. Por otra parte, la extensión de la democracia puede resultar incompatible con los objetivos estratégicos y de seguridad de Estados Unidos en determinadas regiones - por ejemplo, la España franquista. En último término, durante mucho tiempo resultó difícil promover el lenguaje democrático cuando quedaban en suelo americano asignaturas pendientes al respecto, como la pervivencia de la discriminación contra los afroamericanos. Sin embargo, de estas contradicciones no puede deducirse automáticamente que el mensaje democrático sea una simple coartada de intereses y prejuicios menos confesables -estratégicos, económicos, racistas...-, tal como parece desprenderse de trabajos clásicos del estilo de los de David F. Schmitz ${ }^{9}$. Washington puede haber rebajado en múltiples ocasiones el tono de su discurso pro-democrático en virtud de otro tipo de preferencias, pero eso no significa que haya renunciado del todo a ese propósito. En países aliados con gobiernos dictatoriales, Estados Unidos pudo haber utilizado las herramientas de la diplomacia cultural para ejercer a largo plazo una pulsión a favor de su democratización: "hay pruebas suficientes (...) para sugerir que los programas de intercambio educativo y cultural han jugado un papel clave aunque hasta ahora ha recibido poca atención-en la transferencia política de ideales democráticos" (p. 26).

8 CULL, Nicholas J.: "Public Diplomacy: Taxonomies and Histories", The Annals of the American Academy of Political and Social Science, vol. 616 (2008), pp. 31-54. Cita en la p. 32.

9 SCHMITZ, David F.: Thank God They're On Our Side. The United States and Right-Wing Dictatorships, 1921 1965, Chapel Hill, The University of North Carolina Press, 1999. 
Lorenzo Delgado y Pablo León tratan de probar esta afirmación en sus aportaciones, que se centran respectivamente en la estrategia y los mensajes de la diplomacia pública estadounidense en España. En ambos casos se puede comprobar la mala conciencia inicial de muchos decisores estadounidenses a la hora de establecer vínculos con la dictadura franquista. Unos escrúpulos que, aunque no se resalte en el libro, no eran nuevos. La ejecución de tareas propagandísticas resultaba, per se, contraria a la tradición liberal americana, ya que se contemplaba como un intento de manipulación de la opinión pública, y por ello, un ataque a la libertad de los ciudadanos de otros países. De esta manera, la diplomacia pública no sólo fue vista, en alguna medida, como un mal menor derivado de los crecientes compromisos internacionales de Estados Unidos, sino que fue objeto de pugnas internas que redujeron su eficacia; sobre todo en aquellos países, como España, donde la promoción de los ideales americanos podía contrariar los intereses estratégicos de Washington. Ya había ocurrido durante las dos guerras mundiales ${ }^{10}$, y volvió a pasar tras la aproximación hispano-estadounidense simbolizada por los pactos de 1953. Algo que sirve para explicar los distintos cambios en el método y el discurso de la propaganda norteamericana entre 1945 y 1975. Los momentos coincidentes con la condena internacional al franquismo fueron meses en los que la propaganda estadounidense no dejó de mostrar su oposición al sistema político español. Cuando hizo su aparición la Guerra Fría, el acercamiento bilateral vino acompañado de un intento permanente por "evitar identificarse con cualquier política del gobierno español que no sea necesaria para la implementación eficiente de los acuerdos" hispano-estadounidense de 1953 (p. 98). Sin embargo, ya en los cincuenta, la diplomacia pública se centró en los "líderes de la vida pública", que en España se identificaban con aquellos sectores de la sociedad que podían facilitar la ejecución y permanencia de los actos; y en la década siguiente también en quienes podían ser los líderes - tanto favorables como opuestos al régimen- de una transición pacífica a la democracia, una vez desaparecido Franco. Los agentes culturales de los Estados Unidos nunca pararon de hablar en España, para una audiencia reducida, del funcionamiento de la democracia americana. Lo hicieron a través fundamentalmente de sus publicaciones -Noticias de Actualidad, Atlántico, etc.-, y con el objeto de hacer patente que un gobierno representativo no era sinónimo de una sociedad dividida e ineficiente. Pero fue precisamente la eficiencia, o más concretamente, el paradigma de la "modernización", que popularizaron en los sesenta académicos como Walter W. Rostow, lo que acabó marcando la pauta de los programas de diplomacia pública en España. Éstos se dirigieron al "desarrollo del crecimiento económico y la integración de España en el entramado europeo, al objeto de expandir y reforzar sus bases sociales para la evolución hacia un sistema político de base popular" (p. 77). De ahí que, por ejemplo, los esfuerzos de los programas de intercambio y de ayuda se acabasen dirigiendo a apoyar la reforma educativa plasmada en la Ley General de Educación de 1970; y los mensajes no dejasen de propugnar un deseo de imitación a partir de la difusión de: los aspectos más atractivos de la sociedad estadounidense -

10 WOLPER, Gregg: "Wilsonian Public Diplomacy: The Committee on Public Information in Spain”, Diplomatic History, vol. 17, nº 1 (1993), pp. 17-34. LEÓN AGUINAGA, Pablo: "The Trouble With Propaganda: the Second World War, Franco's Spain and the Origins of U.S. Post-War Public Diplomacy”, International History Review, Vol. 37, nº 2 (2015), pp. 342-365. 
progreso social, económico y cultural-, los efectos de la ayuda americana en España, y el liderazgo internacional de los Estados Unidos frente a la Unión Soviética.

La reacción española a los esfuerzos de la propaganda estadounidense puede medirse parcialmente a través de los capítulos de Francisco Javier Rodríguez y Neal Rosendorf - del que hablaremos al tratar de su libro. El primero procura rastrear las razones del fracaso en España de los American Studies, bajo los que se agrupan aquellas disciplinas -fundamentalmente historia, arte, literatura y pensamientodestinadas a potenciar la alta cultura norteamericana. Su promoción en España se vio lastrada por una serie de resistencias internas, entre las que cabe destacar dos. En primer lugar, las diferencias de criterio en cuanto al desarrollo del programa Fulbright, al que España se adhirió en 1958. Los norteamericanos deseaban que el dinero de sus becas se destinara fundamentalmente a la formación de españoles en materias relacionadas con los American Studies, para que continuasen el camino iniciado por los profesores americanos que se estaban desplazando temporalmente a las universidades españolas. Por su parte, el gobierno español buscaba el envío a Estados Unidos de técnicos que pudiesen trabajar a su vuelta en los sectores punteros del país. Acabó prevaleciendo el criterio estadounidense, pues hubo muchos más becados en las áreas de humanidades y ciencias sociales que ciencias experimentales. Sin embargo, el programa entró en crisis a finales de la dictadura, debido al descenso de las aportaciones realizadas al mismo por parte de Estados Unidos. En segundo lugar, los "estudios americanos" chocaron con la resistencia de distintas dinámicas establecidas a nivel local -el carácter cerrado de la universidad, la preferencia por el inglés británico frente al norteamericano-, que acabaron haciendo imposible su asentamiento.

El libro se completa con otras dos aportaciones de distinto valor. El texto de Rosa Pardo supone un intento de poner en un contexto más europeo a la dictadura franquista, mediante un intento de comparación con su homóloga en la Península Ibérica: el salazarismo portugués. La evolución parece marcada por los contrastes, ya que si a finales de los años cuarenta la posición estadounidense frente a Portugal era más amistosa que ante España, a resultas de la aliadofilia lusa durante la II Guerra Mundial, a comienzos de la década de los setenta la situación parecía haber dado un giro de ciento ochenta grados. Los portugueses se encontraban airados por la posición de Washington frente a procesos de descolonización como los de Angola y Mozambique, mientras que España parecía estar recogiendo los frutos sembrados tras los Pactos de 1953 y las duras renegociaciones de los mismos a lo largo de los años sesenta. Aun así, el capítulo arroja conclusiones similares para ambos países: "Debido a una mezcla de oportunismo político y presiones por parte de la superpotencia, tanto Franco como Salazar cedieron bases militares a cambio de ayuda para solventar problemas relacionados con la seguridad, la integración internacional o la debilidad económica" (p. 57). Lo cual vuelve a poner sobre el tapete la primacía de los objetivos estratégicos en la acción exterior americana, sin negar que el apoyo a las "dictaduras ibéricas" pudo tener un "efecto modernizador" (p. 58). De mucha menor relevancia es el capítulo-testimonio del Embajador Mark Asquino, que residió en España durante dos temporadas: primero como profesor becado por el programa Fulbright en el momento de la muerte del general Franco (1975-1976), y luego como director del centro cultural de los Estados Unidos en Madrid. Su relato está cuajado de testimonios personales que, sin mayor ambición, buscan mostrar su apoyo al proceso de democratización iniciado en España tras 1975. 
Lorenzo Delgado intenta dar contestación al interrogante principal del libro en un capítulo de conclusión cuyo título resulta ilustrativo: "Consistencia y credibilidad". Aunque trata de poner en valor el trabajo de la diplomacia pública estadounidense en España como promotora de la democracia, sus observaciones finales nos colocan casi en la posición de partida. Primero, por la dificultad de medir los resultados de una actividad como la propaganda - entendida en sentido amplio-, cuyos logros excluyen cualquier posibilidad precisa de cuantificación. En segundo lugar, porque ante la falta de evidencias, el balance que se presente no elude el tono recriminatorio propio de los estudios estratégicos clásicos en torno a la relación España-Estados Unidos. Éstos habrían asumido una "política de 'baja intensidad' en la promoción de la democracia", plasmada en el mayor volumen de recursos dedicados al mantenimiento de las bases militares que a la diplomacia pública, y en el hecho de que la expansión de la democracia habría resultado meramente instrumental: interesaba sólo en la medida en que una España plural mejorase la estabilidad de las instalaciones de Torrejón, Rota, Zaragoza, etc. Tal afirmación no deja de ser un juicio de valor, posible pero no demostrable. Más allá de aceptar la ausencia de fuentes para probarlo, y la necesidad de ceñirse a lo que éstas pueden decirnos, hasta que se encuentren nuevos indicios o estrategias de investigación, se debe huir definitivamente del disgusto que pueda producirnos la dictadura franquista. Resulta fácil acusar a los Estados Unidos de no hacer lo suficiente para apoyar una transición más rápida y efectiva hacia un gobierno representativo en España; pero no parece tan sencillo darse cuenta de que ese apoyo hubiera podido suponer una intromisión en los asuntos internos de España que, para unos ojos actuales, hubiera sido cuando menos éticamente cuestionable. Scott-Smith tiene razón al proponer una diferenciación entre promoción de la democracia y ayuda a la democracia; la primera puede llegar a significar el uso de la coacción, mientras que la segunda implica pensar en el largo plazo y asumir no sólo que el resultado será incierto, sino que resultará imposible de medir.

Como difíciles de valorar resultan los esfuerzos de los gobiernos de Franco por mejorar la imagen de España en los Estados Unidos, que centran el último libro de Neal Rosendorf, actualmente profesor de relaciones internacionales en la Universidad de Nuevo México. La perspectiva del trabajo reproduce la trayectoria académica de su autor -a caballo entre la historia, el hispanismo y la ciencia política- y las influencias de sus maestros en Harvard: Akira Iriye y Joseph Nye. Del primero ha heredado la preferencia por los enfoques trasnacionales y el papel de la cultura en la esfera global. No obstante, el discípulo ha dado una vuelta de tuerca a las aproximaciones del maestro, apartando el foco de los Estados Unidos, para colocarlo no sólo sobre los receptores de la influencia cultural americana -en este caso España-, sino también sobre los intentos de esos receptores por utilizar las mismas armas de la diplomacia pública para tratar de influir en el gobierno y la sociedad estadounidenses. De Nye ha tomado Rosendorf el gusto por las etiquetas teóricas capaces de abarcar una gran cantidad de acciones aparentemente inconexas: la ya manida de soft power o la más actual de national branding. Su interés por el caso español emana de su tesis doctoral sobre las actividades cinematográficas en España de Samuel Bronston, el famoso productor de El Cid, 55 días en Pekín o La caída del imperio romano. Todos estos ingredientes conforman el trasfondo de Franco Sells Spain to America, un intento por dotar de coherencia a los esfuerzos desplegados por la dictadura franquista para lavar su imagen al otro lado del Atlántico. 
Tomados por separado, los distintos capítulos -muchos de los cuales habían aparecido en forma de artículos o cotribuciones a volúmenes colectivos ${ }^{11}$ componen valiosas aportaciones, ya que reconstruyen con bastante fidelidad algunos procesos, hasta ahora conocidos sólo de forma parcial e inconexa, que la dictadura aprovechó para congraciarse con una parte de la ciudadanía norteamericana. El estudio comienza con el turismo, de la mano de empresas, como American Express o Trans-World Airlines, que vieron ya en la España de los primeros cuarenta la alternativa turística a una Europa envuelta en la II Guerra Mundial. La dictadura recogió el testigo mediante la apertura en 1949 de una oficina de turismo en Nueva York -que actuó realmente como agencia de propaganda- y la eliminación de las restricciones que dificultaban la llegada de turistas americanos -como la exigencia de visados. Sobre estos cimientos, estadounidenses y españoles consiguieron, a través de la construcción del Hotel Castellana Hilton, la inclusión de España en las guías europeas escritas por algunos de los más prestigiosos escritores de viajes como Temple Fielding, y las campañas de promoción del Ministerio de Información y Turismo, que a lo largo de los cincuenta y sesenta el flujo de viajeros procedentes de Norteamérica no dejase de crecer. En el caso del cine, fueron las productoras estadounidenses las que, con el aumento de los costes de las grandes producciones a lo largo de los cincuenta, comenzaron a buscar localizaciones menos costosas para sus rodajes, poniendo sus miras en España. El camino abierto por United Artists fue seguido muy pronto por Samuel Bronston, una mezcla de empresario, productor y aventurero nacido en Rusia y que, de la mano de un vástago de los DuPont, consiguió el dinero necesario para rodar en España algunos de sus grandes éxitos. Bronston estableció una especie de relación simbiótica con el franquismo, que no dudó en agasajar y condecorar al cineasta, a cambio de introducir temas españoles en sus películas, o de rodar documentales a favor del régimen. La ruina de los estudios Bronston en Las Rozas (Madrid) no supuso el fin de los grandes rodajes en España, aunque su número disminuyó según se acercó la década de los setenta, y los directores americanos mostraban sus preferencias por otros lugares. Sobre este trasfondo turístico y fílmico Rosendorf coloca distintas iniciativas desarrolladas bien por la oficina española de turismo en Nueva York, bien por el Ministerio de Información y Turismo, a lo largo de los cincuenta y sesenta: desde la publicación mensual de la Spanish Newsletter hasta la organización de los actos de celebración del 250 aniversario de Fray Junípero Serra, pasando por la inspiración de artículos en revistas estadounidenses como Cosmopolitan, Vogue o Variety. Todo ello culminaría en la construcción del pabellón español en la Exposición Internacional de Nueva York en 1964-65. Una empresa que la dictadura transformó, gracias a una inversión sin precedentes de siete millones de dólares, en un enorme escaparate de la cultura, la política, y la economía españolas.

Si los mensajes de la diplomacia pública americana en España estuvieron lastrados por el apoyo a la dictadura franquista, las campañas de imagen de ésta en

11 ROSENDORF, Neal M.: "Be El Caudillo's Guest: The Franco Regime's Quest for Rehabilitation and Dollars after World War II via the Promotion of U.S. Tourism to Spain”, Diplomatic History, vol. 30, no 3 (2006), pp. 367-407; "Hollywood in Madrid: American Film Producers and the Franco Regime", Historical Journal of Film, Radio and Television, vol. 27, $\mathrm{n}^{\circ} 1$ (2007), pp. 77-109; y "Hollywood, Dictatorship and Propaganda: Samuel Bronston's Special Relationship with the Franco Regime, 1957-1973”, en OSGOOD, K.E. y ETHERIDGE, B.C. (eds.): The United States and Public Diplomacy. New Directions in Cultural and International History, Leiden and Boston, Martinus Nijhoff Publishers, 2010, pp. 103-133. 
Estados Unidos tampoco pudieron sustraerse a las polémicas generadas por algunas políticas poco amigables a ojos norteamericanos. Rosendorf le dedica un capítulo a la ausencia de libertad religiosa en España, que resultaba especialmente onerosa para los residentes extranjeros que profesaban el protestantismo, y que ya había dilatado las negociaciones políticas estadounidenses previas a los pactos de 1953. Aunque esta política se iría relajando con el paso de los años, serviría como recordatorio de las limitaciones con que pueden tropezar las empresas de relaciones públicas al ser contrastadas con los aspectos menos halagüeños del país que las patrocina.

El libro de Rosendorf se inserta así dentro de las nuevas corrientes en el estudio de la americanización, para las que, en palabras de Richard Pells "la relación cultural de América con el resto del mundo no ha sido tan unívoca (...) como reclaman políticos e intelectuales. En su lugar, lo que se ha dado es una compleja interacción entre culturas diferentes y crecientemente heterogéneas"; y aquí, "los Estados Unidos han sido tanto receptores como creadores" 12 . Sin embargo, admitir que, a resultas de sus contactos, España influyó en Estados Unidos, no quiere decir que lo hiciera con el mismo nivel de intensidad. Las dos naciones podrían tener problemas de imagen parecidos, y procurar influirse mutuamente, pero la capacidad de acción de una superpotencia no puede ser la misma que la de un país de segundo nivel. Como recuerda acertadamente Richard Kuisel: "Es un error ignorar el dominio político, económico y militar americano (...). Las transferencias culturales (...) pueden ser una carretera de dos direcciones, pero la mayoría del tráfico ha estado siguiendo la misma dirección"13.

Dehecho, el trabajo de Rosendorfmagnifica el alcance de las iniciativas franquistas, llevado por dos preconcepciones. La primera radica en el deseo de utilizar categorías actuales para analizar una realidad en muchos aspectos lejana en el tiempo, como es la de la España de mediados del siglo XX. El autor busca oponerse frontalmente a quienes señalan que el éxito de la marca España, y con él la historia del desarrollo económico español, son posteriores a 1975. Para ello asegura que "en la medida en que podemos hablar de la reconstrucción de la marca España, necesitamos retrotraer su génesis hasta el período inmediatamente posterior a la II Guerra Mundial, y a la determinación estratégica de Franco de reintegrar a España en la comunidad de las naciones, en sus propios términos" ( $p$ 199). Esto presupone encuadrar todas las historias narradas en este libro dentro de un esfuerzo consciente y organizado, encabezado por el propio dictador. La agencia del propio Franco se deduce no del rastro documental, sino del hecho de que, cada vez que alguna de las iniciativas de imagen suscitaba una controversia interna en el gobierno, la decisión final era en la mayoría de los casos favorable a la empresa. Esta segunda preconcepción -el papel central de Franco en todo el proceso- trasluce un cierto desconocimiento de las dinámicas de funcionamiento del gobierno en época de Franco, que hacen en realidad muy difícil conocer el papel real del mandatario. Rosendorf tiene razón al afirmar que es necesario despejar muchas de las preconcepciones historiográficas sobre el franquismo, pero no puede hacerse al precio de construir una narración contrapuesta.

12 PELLS, Richard: “Commentary: Who's Afraid of Steven Spielberg?”, Diplomatic History, vol. 23, n 3, pp. 495-502. Cita en la p. 498.

13 KUISEL, Richard: "Commentary: Americanization for Historians", Diplomatic History, vol. 24, no 3 (2000), pp. 509-515. Cita en la p. 510. 
La ventaja de los historiadores es que juegan siempre conociendo el final, y sabemos perfectamente que, a la postre, España se democratizó y que, cuando el proceso de transición se puso en marcha, lo hizo con las simpatías de personalidades y grupos del mundo de la política, la cultura y los medios estadounidenses. Pero resulta difícil apuntar el peso real que en ese proceso tuvieron los public diplomats estadounidenses, o los agentes del gobierno español que dirigían campañas de opinión pública en Estados Unidos. El valor de los dos libros aquí considerados radica precisamente en el esfuerzo realizado para documentar la existencia de ambos fenómenos. Sólo por eso merecen ocupar un lugar más que destacado dentro de la historiografía sobre las relaciones España y los Estados Unidos, y también en el marco más general de la historia de la diplomacia pública. Desde ese punto de vista son el resultado de una labor concienzuda y hasta erudita, propia de historiadores con un alto grado de profesionalidad. Cuando su trabajo comienza a fallar es cuando buscan ir más allá de lo que las fuentes pueden soportar, y por lo tanto de las propias fronteras del trabajo del historiador que, llevados por la frustración, todos tenemos la tentación de traspasar en algún momento. 